Review

\title{
Opportunistic Premise Plumbing Pathogens: Increasingly Important Pathogens in Drinking Water
}

\author{
Joseph O. Falkinham, III 1,*, Amy Pruden ${ }^{2}$ and Marc Edwards ${ }^{2}$
}

1 Department of Biological Sciences, Virginia Tech, 5008 Derring Hall, Blacksburg, VA 24060, USA

2 Via Department of Civil and Environmental Engineering, Virginia Tech, 401 Durham Hall, Blacksburg, VA 24060, USA; E-Mails: apruden@vt.edu (A.P.); edwardsm@vt.edu (M.E.)

* Author to whom correspondence should be addressed; E-Mail: jofiii@vt.edu;

Tel.: +1-540-231-5931; Fax: +1-540-231-9307.

Academic Editor: Mark W. LeChevallier

Received: 1 April 2015 / Accepted: 3 June 2015 / Published: 9 June 2015

\begin{abstract}
Opportunistic premise plumbing pathogens are responsible for a significant number of infections whose origin has been traced to drinking water. These opportunistic pathogens represent an emerging water borne disease problem with a major economic cost of at least $\$ 1$ billion annually. The common features of this group of waterborne pathogens include: disinfectant-resistance, pipe surface adherence and biofilm formation, growth in amoebae, growth on low organic concentrations, and growth at low oxygen levels. Their emergence is due to the fact that conditions resulting from drinking water treatment select for them. As such, there is a need for novel approaches to reduce exposure to these pathogens. In addition to much-needed research, controls to reduce numbers and human exposure can be instituted independently by utilities and homeowners and hospital- and building-operators.
\end{abstract}

Keywords: opportunistic premise plumbing pathogens; Mycobacterium avium; Legionella pneumophila; Pseudomonas aeruginosa 


\section{Introduction}

Opportunistic premise plumbing pathogens are waterborne microorganisms that are normal inhabitants of premise plumbing and cause infections in individuals with predisposing conditions, such as advanced age ( $>70$ years), cancer, or immunodeficiency. Recognized opportunistic premise plumbing pathogens include Legionella pneumophila, Mycobacterium avium and other nontuberculous mycobacteria (NTM), and Pseudomonas aeruginosa. A recently published study showed that the incidence of cases of Legionella spp. in the United States was estimated to be 13,000 per year, and that for the nontuberculous mycobacteria was 16,000 annually over the period 2004-2007 [1]. Further, the annual economic cost of those infections in the United States was quite high; namely over \$430 million for Legionella spp. and \$425 million for nontuberculous mycobacterial infections [1]. This is likely an underestimate as the infections reported were only those involving hospitalization and did not include Legionella infections that were treated outside of hospitals and also did not include the cost of litigation involved in Legionella infections. Unlike the classic waterborne pathogens, such as Salmonella, Shigella, and Escherichia coli, the opportunistic premise plumbing pathogens are native to the premise plumbing environment and ideally adapted to survival, growth, and persistence in drinking water distribution systems and premise plumbing. Premise plumbing has several unique features, such as high surface to volume ratio, unique pipe materials, low organic carbon levels, and periods of stagnation, that select for correspondingly distinct communities of microorganisms. Toward the objective of alerting the drinking water community, we provide a first review of the characteristics of opportunistic premise plumbing pathogens.

\section{Opportunistic Premise Plumbing Pathogens and Their Public Health Impact}

Evidence is emerging that both the number of opportunistic premise plumbing pathogens in drinking water and the number of individuals who are at risk of infection by these pathogens are increasing. Thus, we need to expand our knowledge beyond the limited number of model pathogens reviewed here to others, for example: Stenotrophomonas, Aeromonas, and Acinetobacter. Over the period 2000-2009, the incidence of Legionella spp. infections in the United States increased almost 200\%, from 0.39 cases per 100,000 persons in 2000 to 1.15 in 2009 [2]. For P. aeruginosa, although yearly incidence figures are not available because reporting is not required, a total of almost 11,000 hospital-acquired $P$. aeruginosa bloodstream, pneumonia, and urinary tract infections were identified in the United States over the period of January 1992 through May 1999 [3]. For nontuberculous mycobacteria, both the number of isolates (majority are Mycobacterium avium) and cases has increased. Specifically, the frequency of isolation of nontuberculous mycobacteria from clinical specimens in Ontario, Canada has risen from 9.1 to 14.1/100,000 over the period 1997 to 2003; a mean annual increase of 8.4\% [4]. Pulmonary nontuberculous mycobacterial hospitalizations increased from 2.1 to 2.4 per 100,000 in Florida; a 3.2\% annual increase [5]. As with the numbers for Legionella spp. infection, that value is an underestimate as the majority of nontuberculous mycobacteria-infected individuals are not hospitalized. The increase in nontuberculous mycobacterial pulmonary disease is predominantly in women $(6.5 \%$ per year in Florida and $4.6 \%$ in New York) [5].

Increases in both the proportion of older individuals and those that are immunodeficient are major contributors to the increases in opportunistic premise plumbing pathogen infection; the proportion of 
individuals over 60 years will be $25 \%$ by 2025, up from $16.1 \%$ in 2000 [6]. The effect of an aging population on infection and disease caused by these waterborne pathogens is illustrated by the 6-fold increased frequency of M. avium lung disease in the United States of 15/100,000 in the general population compared to 100/100,000 amongst individuals over 60 years [5]. The same trend holds true for L. pneumophila infection [2]. In like fashion, as the number of immunodeficient individuals (e.g., cancer, chemotherapy, and transplantation patients), who are more susceptible to opportunistic pathogen infection, increase, so will the incidence of infection and disease. Changes in building plumbing practices and disinfection emphasizing water conservation might also be increasing the likelihood of the occurrence of these waterborne pathogens and disease [7].

An integrated analysis of the two simultaneous trends of increased opportunistic premise plumbing pathogen occurrence and increased infected individuals is needed in order to identify strategies for better protecting public health now and in the future. It is the objective of this review to: (1) describe the characteristics of opportunistic premise plumbing pathogens that lead to their selection in drinking water systems and premise plumbing (Section 3); (2) identify the challenge of this group of pathogens to the current water treatment paradigm (Section 4); (3) describe methods for expanding knowledge of opportunistic premise plumbing pathogens in premise plumbing (Section 5); and (4) consider how an integrated understanding of the behavior of these waterborne opportunistic pathogens can better inform methods for reducing their numbers in premise plumbing (Section 6). Toward those ends, we present a review of current knowledge of Legionella pneumophila, Mycobacterium avium, and Pseudomonas aeruginosa as exemplars and not as independent, unique waterborne pathogens.

\section{Selection for Opportunistic Premise Plumbing Pathogens in Drinking Water Systems and Premise Plumbing}

Characteristics of opportunistic premise plumbing pathogens contributing to their persistence in drinking water distribution systems and premise plumbing include: (1) disinfectant-resistance, (2) biofilm-formation; (3) survival and growth in phagocytic free-living amoebae; (4) growth at low oxygen concentrations; and (5) ability to grow at low levels of organic carbon. These characteristics mean that these waterborne pathogens are ideally adapted to the unique conditions of premise plumbing. Compared to E. coli, the CT99.9\% for water-adapted cells of L. pneumophila is 1050-fold [8], M. avium is 2000-fold [9], and P. aeruginosa is 40-fold [10] higher; all three are inherently disinfectant-resistant. Thus, standard disinfectant dosages for drinking water treatment will essentially kill off all but these opportunistic pathogens. Consequently, these relatively slower growing premise plumbing pathogens are able to consume the available organic carbon without competition. Biofilm-formation provides a mechanism to prevent washing out of microorganisms in flowing systems, such as pipes and has been documented for L. pneumophila [11], M. avium [12], and P. aeruginosa [13]. Further, for all three, residence in biofilms substantially increases their resistance to disinfectants [12-14]. Resistance to phagocytic killing by free-living amoebae is also a shared characteristic of these opportunistic pathogens. L. pneumophila and M. avium are not killed, but survive and grow in phagocytic, free-living amoebae [e.g., Acanthamoeba, Vermamoeba (nee, Hartmanella)]; they are amoebae-resisting microorganisms (ARM) [15]. Further, amoebae-grown L. pneumophila [16] and M. avium [17] are more virulent than cells grown in laboratory medium. In contrast, phagocytosis of $P$. aeruginosa results in rapid killing of 
Acanthamoeba castellanii [18]. Quite possibly, low organic carbon concentrations in drinking water may not prevent the growth of all OPPPs. For example, M. avium thrives at assimilable organic concentrations (AOC) as low as $50 \mu \mathrm{g} / \mathrm{L}$ [19]. Further, growth of $M$. avium is stimulated by omnipresent humic and fulvic acids in surface waters [20,21]. P. aeruginosa can even grow in distilled water [22]. As it is likely that L. pneumophila persists in drinking water systems and premise plumbing in amoebae, rather than as free living cells [15], its growth in water of low organic concentrations is dependent upon growth by phagocytosis of other microorganisms by amoebae.

Periods of stagnation in premise plumbing can increase numbers of opportunistic premise plumbing pathogens, as they are capable of growth even at low oxygen levels, though not under conditions of anaerobiosis. For example, L. pneumophila numbers did not fall in hot water heaters when not in use [23], M. avium can grow at $6 \%$ and $12 \%$ oxygen [24] and $P$. aeruginosa can grow in the absence of oxygen using nitrate as a terminal electron acceptor [25]. It might prove to be the case that either high or low oxygen concentrations would lead to the reduction in numbers of these microaerobic bacterial pathogens. High oxygen concentrations were associated with low NTM numbers in surface waters $[20,26]$ and the same holds true for L. pneumophila [23].

Taken together, a review of the common characteristics of opportunistic premise plumbing pathogens suggests they are ideally suited for growth in premise plumbing. However, for remediation efforts to be successful in reducing their numbers, the premise plumbing environment must be changed. Opportunistic premise plumbing pathogens survive disinfection and are not washed out of pipes because of biofilm-formation. Phagocytic, free-living amoebae are also not going to reduce their numbers as either the bacteria grow within the amoebae (i.e., L. pneumophila and M. avium) or kill the amoebae (i.e., $P$. aeruginosa). In the absence of competitors, these waterborne opportunistic pathogens can utilize even the low concentrations of organic carbon to grow, perhaps not even restricted by low oxygen concentrations characteristic of stagnation. The paucity of literature on the response of these pathogens to oxygen levels is a strong motivator for research initiatives.

\section{Challenge of Opportunistic Premise Plumbing Pathogens to the Current Water Treatment Paradigm}

Current water treatment dogma is based on the epic battles of the 20th century, when waterborne pathogens (e.g., Salmonella, Vibrio) primary originated from fecal contamination of water supplies. Those pathogens are naturally attenuated over the time of exposure to drinking water and by treatment steps including disinfection, because they do not multiply outside of their mammalian host. In contrast, $M$. avium numbers increase with distance from the treatment plant as they multiply in the distribution system [27]. Opportunistic premise plumbing pathogens are not merely transported through pipes, but are actually adapted to growth and persistence in drinking water, especially in building plumbing systems, presenting three challenges to the current paradigm for water treatment. First, source tracking within a water distribution system is meaningless, as the likelihood of amplification and detection increases in the more distal parts of the system. Second, disinfection using the guidance developed for E. coli, rather than based on susceptibility of these disinfectant-resistant opportunistic pathogens, can actually select for their predominance. Third, the current location for regulatory compliance sampling, at the treatment plant effluent, is actually where the opportunistic premise plumbing pathogens are least likely 
to be detected, and utilities do not sample stagnant water in buildings where they are most likely to be detected.

Experience has indicated that it might be impossible to fully eradicate these opportunistic pathogens from premise plumbing in homes, condominiums, apartments, hospitals and office buildings [28,29]. In fact, a recent survey identified detectable levels of Legionella pneumophila in about $40 \%$ of homes sampled [30]. Another survey showed that $70 \%$ of biofilm samples from showerheads collected from homes and institutions across the United States harbored Mycobacterium spp. and of those 30\% had M. avium [31].

Another challenge is that several of the opportunistic waterborne pathogens, including $P$. aeruginosa and L. pneumophila, enter a viable, but nonculturable (VBNC) state [32,33]. Cells in the VBNC state are viable but fail to form colonies on agar media; thus standard culture methods will fail to detect them or provide false low numbers for cells [34]. VBNC cells display respiratory activity (e.g., redox dye reduction), membrane integrity (e.g., membrane permeation by dyes), yet can be counted as cells using fluorescent-in situ-hybridization (FISH) with species-specific 16S rRNA probes or total cells counts [35,36]. The VBNC state is triggered by exposure to stress associated with exposure to: disinfectants, reduced temperature, toxic oxygen metabolites, or starvation [34,35]. Cells of both L. pneumophila and P. aeruginosa in suspension or in biofilms have been shown to enter the VBNC state and, in that state, the number of colony-forming cells were two-orders of magnitude lower than the total number of cells by FISH [36]. Although colony counts for M. avium in drinking water are the same as counts by qPCR [37], there are reports of VBNC in mycobacteria [35]. In addition to detection of the VBNC state, methods have been developed for "resuscitation" of VBNC cells, which include phagocytosis by amoebae [38,39].

\section{Isolation of Putative Opportunistic Premise Plumbing Pathogens}

It is important to recognize that opportunistic premise plumbing pathogenic isolates detected by standardized testing, such as L. pneumophila serotype 1, are not necessarily the only pathogenic members of their genera. In fact, because reporting is low or not required in most situations (except for L. pneumophila), and most infections go unidentified, these opportunistic plumbing pathogens that we are aware of are likely only the tip of the iceberg. Further, in a practical sense, it would be of value to identify novel opportunistic premise plumbing pathogens to anticipate future emerging waterborne pathogens and associated disease to better inform effective engineering control of waterborne disease. Such an objective requires guidance for detection of emerging premise plumbing pathogens.

Toward that goal, we first identify two emerging pathogens that appear to be members of this group of opportunistic premise plumbing pathogens, yet their source of infection has not been clearly elucidated. Injured U. S. troops in the Middle East were found to be infected by Acinetobacter baumanii, a heretofore rarely encountered opportunistic human pathogen [40]. A. baumanii has been isolated from drinking water [41], survives and grows in Acanthamoeba sp. [42] and is approximately 1000-times more resistant to chlorine than E. coli [43]. Another emerging opportunistic pathogen is Aeromonas hydrophila. It is found in drinking water [44], forms biofilms [45], and is 50-times more chlorine-resistant than E. coli [46].

To detect novel emerging waterborne opportunistic pathogens the following methods for isolation are offered. The approaches are based on the common, shared characteristics of the opportunistic premise plumbing pathogens reviewed above (Section 2). It is probable that a substantial proportion of the 
microbes isolated will not be pathogenic. However, they will share some characteristics in common with the opportunistic premise pathogens (e.g., disinfectant-resistance, amoebae-resisting, and biofilm-formation). In as much the number of individuals expected to be more susceptible to microbial infections is increasing, it is prudent to be alert to emerging waterborne pathogens. At the outset of this discussion it should be noted that the emerged and new opportunistic premise plumbing pathogens can be in a VBNC state and detection by colony formation might fail [34-36]. Consideration should be given to providing "recovery" conditions for cells in the VBNC state, before proceeding with detection based on colony formation on agar media. "Recovery" conditions include incubation in broth media, incubating samples or cells suspensions in toxic oxygen metabolite scavengers (e.g., pyruvate or mannitol), or even incubation in amoebae $[34,35,38,39]$.

\subsection{Selection for Amoebae-Resisting Microorganisms}

One of the mechanisms contributing to the survival and persistence of waterborne bacteria in drinking water distribution systems and premise plumbing is shelter from disinfectant provided by phagocytic amoebae [47]. The most direct way for isolating and identifying such bacterial species (and candidate premise plumbing pathogens) is to recover amoebae and protozoa from drinking water or biofilm samples $[15,48,49]$. Those methods involve collection of amoebae by low speed centrifugation $(1000 \times g)$, washing the pelleted amoebae free of suspended microbes in the supernatant liquid. Subsequent lysis of the washed amoebae with low concentrations of detergent (e.g., 0.1\% Tween 80 or Triton X100) and spread plating on medium suitable for growth should yield colonies resulting from any intracellular bacteria $[15,49]$. Fortunately, most bacteria are relatively resistant to the low detergent concentrations employed to lyse the amoebae. As many bacterial stains will stain cells within amoebae (e.g., the Gram-stain or the acid-fast stain), amoeba concentrates can be rapidly screened to determine whether they harbor intracellular bacteria before lysis. Employing the approach of first isolating amoebae and then amoebae-resisting microorganisms, methylobacteria, mycobacteria, and Legionella were recovered from a hospital water network [49]. In another study, amoebae in water yielded: A. baumanii, A. hydrophila, L. pneumophila, Methylobacterium mesophilicum, M. avium, P. aeruginosa, and Stenotrophomonas maltophilia [15]. This approach also has the added advantage of providing "recovery" conditions for cells in the VBNC state, as has been shown for L. pneumophila [39].

\subsection{Selection for Disinfectant-Resistant Microorganisms}

One of the characteristics shared by the opportunistic premise plumbing pathogens is their resistance to disinfectants (e.g., chlorine, chloramine) used in water treatment. As water in some distribution systems and premise plumbing has a residual disinfectant concentration, any surviving microbe in those habitats must be disinfectant-resistant. Amoebae can enhance resistance of resident bacteria, particularly when amoebae are in the cyst form, and protect cells that are not inherently disinfectant-resistant (e.g., Legionella spp.) [50]. Disinfectant-residual can not only select for resistant cells, but also diminish numbers of disinfectant-sensitive competitors, allowing plumbing pathogens to proliferate utilizing available organic carbon. Thus, disinfectant-resistance can also be used as a selective measure to isolate premise plumbing pathogens. Microorganisms can be directly selected by adding a disinfectant to a water or 
biofilm sample at a concentration high enough to kill E. coli, but not so high that all microbes are killed (e.g., 1 ppm for 30, 60, and $120 \mathrm{~min}$ ).

\subsection{Selection of Biofilm-Forming Microorganisms}

Another shared characteristic of opportunistic premise plumbing pathogens is their tendency to adhere to surfaces and proliferate in biofilms. Biofilm-formation is essential for persistence and survival of a microorganism in a flowing pipe system. This is particularly the case for slowly growing opportunistic pathogens such as the mycobacteria and Legionella; their growth rates are not high enough to replace cells lost due to liquid flow. Biofilm-formation, signaled by aggregation of cells in culture, may also be a corollary of amoebae-resistance as amoebae phagocytosis is an important factor governing the population composition of biofilms. Coupons that are composed of different pipe materials (e.g., copper, PVC, or stainless steel) can be placed in a water sample for $2-6 \mathrm{~h}$ at room temperature and adherent microorganisms can be scraped off or suspended by rapid mixing after gentle washing to remove cells from the water. In this approach, the pipe material coupon acts as a selective agent to pull adherent microorganisms out of suspension with microorganisms displaying different hierarchies of adherence. For example, M. avium adherence differs significantly between pipe materials; adherence is highest to galvanized steel, and lowest to glass [51]. In a study of adherence of L. pneumophila and $P$. aeruginosa to pipe materials used in premise ("domestic") plumbing, it was shown that $P$. aeruginosa failed to adhere to copper surfaces but L. pneumophila did adhere [36]. The authors ascribed this observation to the reported sensitivity of $P$. aeruginosa to copper ions [36]. Thus it is important to select a surface where one suspects the opportunistic pathogen is in the biofilm.

\section{Measures to Reduce OPPPs}

\subsection{Introduction to Remediation}

There are four levels where remediation measures can be imposed: (i) the water-provider (utility); (ii) a residential building manager; (iii) in a hospital; and (iv) in a single family home, apartment, or condominium. As opportunistic premise plumbing pathogens are rather new, caution should be observed in adopting any remediation measure as they are not based on extensive experience or side-by-side trials, but guided by the characteristics of the microorganisms and factors influencing their presence or absence in drinking water. Further, informing premise owners may be problematic. Although the water, residential building, and hospital industries have existing information transfer networks that would lead to wide dissemination for remediation measures, no such network exists for building managers and homeowners. One solution would be to work through foundations (e.g., NTMir and Cystic Fibrosis Foundations) whose patients are unusually susceptible to infection and disease by opportunistic premise plumbing pathogens.

\subsection{Remediation by Water Providers}

Providers of drinking water (e.g., municipal utilities) could reduce waterborne pathogen numbers by reducing the turbidity of water, as cells of the known plumbing pathogens are relatively hydrophobic and prefer attachment to particulate matter to free suspension in water. For example, turbidity reductions of surface water led to reductions in M. avium numbers [27]. Disinfectant residuals should be maintained 
as waterborne microorganisms can grow in the absence of disinfectants. Evidence that M. avium, other NTM and Legionella are microaerobic, growing equally well at $12 \%$ oxygen and even at $6 \%$ oxygen [24] and that NTM numbers are low in waters of high oxygen [20,26], suggests that hyper-oxygenation might reduce $M$. avium numbers and perhaps those of other OPPPs. Further, absence of oxygen has also been associated with Legionella die off [52]. Nutrient reduction would be expected to reduce opportunist plumbing pathogen numbers as they require low levels of AOC; for example, M. avium requires at least $50 \mu \mathrm{g} \mathrm{AOC/L} \mathrm{[19].} \mathrm{Finally,} \mathrm{water} \mathrm{distribution} \mathrm{system} \mathrm{pipes} \mathrm{could} \mathrm{be} \mathrm{scoured} \mathrm{to} \mathrm{reduce} \mathrm{biofilms} \mathrm{and} \mathrm{thereby}$ reduce one source of pathogens; those released from the biofilms.

\subsection{Remediation by Residential Building Managers}

Residential buildings offer more opportunity for infection by waterborne pathogens (e.g., showers via aerosolization) than office buildings. Measures could include: (i) raising hot water heater temperature, as there are lower number of M. avium in homes with high hot water heater temperatures [46]; (ii) avoiding recirculating hot water, as microorganisms can grow as they traverse the pipes; (iii) installing single unit hot water systems (perhaps instant heaters) to reduce travel time of hot water; (iv) removing all aerators from taps and faucets, as aerators transfer pathogens to air; (v) cleaning and disinfecting all showerheads, as showerheads have high numbers of waterborne pathogens [31]; (vi) replacing showerheads with large hole, low aeration potential as shower aerosols have high pathogen numbers; (vii), consider building-wide disinfection, as microbes grow in absence of disinfectant; and (viii) increasing aeration of water, as OPPPs may be susceptible to toxic oxygen metabolites.

\subsection{Remediation in Hospitals}

Hospitals and long-term care facilities present special problems as patients or residents are unusually susceptible to infection. In addition to employing all the measures for suggested residential buildings, the following measures could be considered: (i) reduce aerosols through filter entrapment (e.g., micro-trapping or paraffin-coated); (ii) installation of an in-building disinfection system; and (iii) microbial filtration in specific locations (e.g., laboratory, equipment preparation, emergency and operating rooms), where patient trauma will have open routes of infection. Such approaches have been shown to be effective in reducing infections caused by L. pneumophila [53], mycobacteria [54], and P. aeruginosa [55]. A common element in all those actions was the reduction of microbial-laden aerosols from sources in the hospitals.

\subsection{Remediation by Homeowners}

A number of remedial measures are available to homeowners, including: (i) using a well-water source if possible, as wells have lower numbers of opportunistic pathogens [56] and their numbers increase during travel in utility distribution systems from treatment plant [27]; (ii) raising the hot water heater temperature $\left(>55^{\circ} \mathrm{C}\right)$ as homes with high hot water heater temperatures are associated with lower mycobacterial numbers [53]; (iii) increasing aeration of water might reduce pathogen numbers as a number of opportunistic pathogens are microaerophilic [23,24] and ought to be susceptible to toxic oxygen metabolites; (iv) removing all aerators from taps and faucets, as aerators transfer microorganisms to air; 
(v) regularly cleaning and disinfecting showerheads; (vi) replacing showerheads with large hole, low aeration potential as showers are sources of pathogen aerosols [31]; (vii) consider installing point-of-use microbiological filters in taps and showers; (viii) using pipe materials that have low biofilm potential, and (ix) reducing the distance from hot water heater to sites of use.

\subsection{Additional Remediation Measures}

Another approach would be to implement ultraviolet (UV) irradiation to kill waterborne microorganisms. Although they are disinfectant-resistant, mycobacteria, Legionella, and pseudomonads are no more resistant to UV as are other bacteria. However, implementation of UV-disinfection may cause problems as UV is mutagenic. For example, at the ultraviolet (UV) dosages required to kill $99.9 \%$ of Escherichia coli cells, the frequency of mutants among survivors is increased 150 to 250-fold [57].

An alternative approach is to consider the microbial populations of premise plumbing and modify the overall community so that opportunistic pathogen numbers are lowered; a probiotic approach [58]. This appears to be an underappreciated action that requires further research and testing. For example, as amoebae serve as amplifying hosts for opportunistic premise plumbing pathogens (perhaps as obligate hosts for growth of L. pneumophila), it follows that reduction in numbers of amoebae could result in decreased number of premise plumbing pathogens and hence reduce human exposure. Research ought to be initiated to identify conditions that result in reduction in numbers of amoebae [15] to see whether this action can reduce opportunistic pathogens numbers in premise plumbing. It is also possible that reduced predation associated with reduction in amoebae numbers would lead to increased numbers of total bacteria and waterborne pathogens or damage to plumbing materials [59], so caution must be taken. An extension of that approach would be to identify water quality parameters that encourage colonization, growth, and persistence of biofilm-microorganisms that compete with premise plumbing pathogens for surface adherence and biofilm formation. Examination of data reported in a recent survey of showerhead biofilm samples [31] indicated that the presence of members of the genus Methylobacterium was associated with the absence of Mycobacterium spp.

\section{Summary}

Evidence is emerging that both the number of opportunistic premise plumbing pathogens in drinking water and the number of individuals who are at risk of opportunistic pathogen infection are increasing. L. pneumophila, M. avium, and P. aeruginosa as exemplars, but there are likely others related and unrelated that exist and go undetected and unreported. An expanded knowledge of the factors in premise plumbing that select for is needed. These characteristics include biofilm-formation, disinfectant resistance, uptake, survival, and proliferation within an amoeba host. Better defining the characteristics that select for a wide range of opportunistic premise plumbing pathogens, known and unknown, could better guide strategies for effective remediation and control and protect public health. 


\section{Acknowledgments}

The National Science Foundation (CBET Award \# 1336650) and the Alfred P. Sloan Foundation, Microbiology of the Built Environment Program provided funding for this work.

\section{Author Contributions}

All three authors contributed equally to this review. All involved in the data collection and paper writing.

\section{Conflicts of Interest}

The authors declare no conflict of interest

\section{References}

1. Collier, S.A.; Stockman, L.J.; Hicks, L.A.; Garrison, L.E.; Zhou, F.J.; Beach, M.J. Direct healthcare costs of selected diseases primarily or partially transmitted by water. Epidemiol. Infect. 2012, 140, 2003-2012.

2. Centers for Disease Control and Prevention (CDC). Legionellosis-United States, 2000-2009. Morb. Mortal. Wkly. Rep. 2011, 60, 1083-1086.

3. National Nosocomial Infections Surveillance. National nosocomial infections surveillance (NNIS) system report, data summary from January 1990-May 1999, Issued June 1999. Am. J. Infect. Control 1999, 27, 520-532.

4. Marras, T.K.; Chedore, P.; Ying, A.M.; Jamieson, F. Isolation prevalence of pulmonary non-tuberculous mycobacteria in Ontario, 1997-2003. Thorax 2007, 62, 661-666.

5. Billinger, M.E.; Olivier, K.N.; Viboud, C.; Montes de Oca, R.; Steiner, C.; Holland, S.M.; Prevots, D.R. Nontuberculous mycobacteria-associated lung disease in hospitalized persons, United States, 1998-2005. Emerg. Infect. Dis. 2009, 15, 1562-1569.

6. United Nations Population Division. World Population Ageing: 1950-2050. Page 462. United Nations Population Division, United Nations, New York, 2002. Available online: http://www.globalaging.org/ruralaging/world/ageingo/htm (accessed on 26 May 2015).

7. Edwards, M.; Rhoads, W.; Pruden, A.; Pearce, A.; Falkinham, J.O., III. Green water systems and opportunistic premise plumbing pathogens. Plumb. Eng. 2014, 42, 63-65.

8. Kuchta, J.M.; States, S.J.; McGlaughlin, J.E.; Overmeyer, J.H.; Wadowsky, R.M.; McNamara, A.M.; Wolford, R.S.; Yee, R.B. Enhanced chlorine resistance of tap water-adapted Legionella pneumophila as compared with agar medium-passaged strains. Appl. Environ. Microbiol. 1985, 50, 21-26.

9. Taylor, R.H.; Falkinham, J.O., III; Norton, C.D.; LeChevallier, M.W. Chlorine, chloramine, chlorine dioxide, and ozone susceptibility of Mycobacterium avium. Appl. Environ. Microbiol. 2000, 66, 1702-1705.

10. Grobe, S.; Wingender, J.; Flemmin, H.-K. Capability of mucoid Pseudomonas aeruginosa to survive in chlorinated water. Int. J. Hyg. Environ. Health 2001, 204, 139-142.

11. Schofield, G.M.; Locci, R. Colonization of components of a model hot water system by Legionella pneumophila. J. Appl. Bacteriol. 1985, 58, 151-162. 
12. Steed, K.A.; Falkinham, J.O., III. Effect of growth in biofilms on chlorine susceptibility of Mycobacterium avium and Mycobacterium intracellulare. Appl. Environ. Microbiol. 2006, 72, 4007-4100.

13. De Beer, D.; Srinivasan, R.; Stewart, P.S. Direct measurement of chlorine penetration into biofilms during disinfection. Appl. Environ. Microbial. 1994, 60, 4339-4344.

14. Cooper, I.R.; Hanlon, G.W. Resistance of Legionella pneumophila serotype 1 biofilms to chlorine-based disinfection. J. Hosp. Infect. 2010, 74, 152-159.

15. Thomas, V.; McDonnell, G.; Denyer, S.P.; Maillard, J.-Y. Free-living amoebae and their intracellular pathogenic microorganisms: Risks for water quality. FEMS Microbiol. Rev. 2010, 34, 231-259.

16. Brieland, J.K.; Fantone, J.C.; Remick, D.G.; LeGendre, M.; McClain, M.; Engleberg, N.C. The role of Legionella pneumophila-infected Hartmanella vermiformis as an infectious particle in a murine model of Legionnaires' disease. Infect. Immun. 1997, 65, 5330-5333.

17. Cirillo, J.D.; Falkow, S.; Tompkins, L.; Bermudez, L.E. Interaction of Mycobacterium avium with environmental amoebae enhances virulence. Infect. Immun. 1997, 65, 3759-3767.

18. Matz, C.; Moreno, A.M.; Alhede, M.; Manefield, M.; Hauser, A.R.; Givskov, M.; Kjelleberg. S. Pseudomonas aeruginosa uses type III secretion system to kill biofilm-associated amoebae. Int. Soc. Microb. Ecol. J. 2008, 2, 843-852.

19. Norton, C.D.; LeChevallier, M.W.; Falkinham, J.O., III. Survival of Mycobacterium avium in a model distribution system. Water Res. 2004, 38, 1457-1466.

20. Kirchner, R.A., Jr.; Parker, B.C.; Falkinham, J.O., III. Epidemiology of infection by nontuberculous mycobacteria. X. Mycobacterium avium, M. intracellulare, and M. scrofulaceum in acid, brown-water swamps of the southeastern United States and their association with environmental variables. Am. Rev. Respir. Dis. 1992, 145, 271-275.

21. Kirchner, R.A.; Parker, B.C.; Falkinham, J.O., III. Humic and fulvic acids stimulate the growth of Mycobacterium avium. FEMS Microbiol. Ecol. 1999, 30, 327-332.

22. Favero, M.S.; Carson, L.A.; Bond, W.W.; Petersen, N.J. Pseudomonas aeruginosa: Growth in distilled water from hospitals. Science 1971, 173, 836-838.

23. Ciesielski, C.A.; Blaser, M.J.; Wang, W.-L. Role of stagnation and obstruction of water flow in isolation of Legionella pneumophila from hospital plumbing. Appl. Environ. Microbial. 1984, 48, 984-987.

24. Lewis, A.H.; Falkinham, J.O., III. Microaerobic growth and anaerobic survival of Mycobacterium avium, Mycobacterium intracellulare and Mycobacterium scrofulaceum. Int. J. Mycobacteriol. 2015, 4, 25-30.

25. Sias, S.R.; Stouthamer, A.H.; Ingraham, J.L. The assimilatory and dissimilatory nitrate reductases of Pseudomonas aeruginosa are encoded by different genes. J. Gen. Microbiol. 1980, 118, 229-234.

26. Brooks, R.L.; Parker, B.C.; Falkinham, J.O., III. Epidemiology of infection by nontuberculous mycobacteria. IV. Isolation from southeastern US soils and waters and correlations with characteristics. Am. Rev. Respir. Dis. 1984, 120, 84-89.

27. Falkinham, J.O., III; Norton, C.D.; LeChevallier, M.W. Factors influencing numbers of Mycobacterium avium, Mycobacterium intracellulare, and other mycobacteria in drinking water distribution systems. Appl. Environ. Microbiol. 2001, 67, 1225-1231. 
28. Kusnetsov, J.; Torvinen, E.; Perola, O.; Nousiainen, T.; Katila, M.-L. Colonization of hospital water systems by Legionellae, mycobacteria and other heterotrophic bacteria potentially hazardous to risk group patients. Acta Pathol. Microbiol. Immunol. Scand. 2003, 111, 546-556.

29. Williams, M.M.; Armbruster, C.R.; Arduino, M.J. Plumbing of hospital premises is a reservoir for opportunistically pathogenic microorganisms: A review. Biofouling 2013, 29, 147-162.

30. Donohue, M.J.; O’Connell, K.; Vesper, S.J.; Mistry, J.H.; King, D.; Kostich, M.; Pfaller, S. Widespread molecular detection of Legionella pneumophila serogroup 1 in cold water taps across the United States. Environ. Sci. Technol. 2013, 48, 3145-3152.

31. Feazel, L.M.; Baumgartner, L.K.; Peterson, K.L.; Frank., D.K.; Harris, J.K.; Pace, N.R. Opportunistic pathogens enriched in showerhead biofilms. Proc. Nat. Acad. Sci. USA 2008, 106, 16393-16399.

32. Bédard, E.; Charron, D.; Lalancette, C.; Déziel, E.; Prévost, M. Recovery of Pseudomonas aeruginosa culturability following copper- and chlorine-induced stress. FEMS Microbiol. Lttr. 2014, 356, 226-234.

33. Bej, A.K.; Mahbubani, M.H.; Atlas, R.M. Detection of viable Legionella pneumophila in water by polymerase chain reaction and gene probe methods. Appl. Environ. Microbiol. 1991, 57, 597-600.

34. Oliver, J.D. The viable but nonculturable state in bacteria. J. Microbiol. 2005, 43, 93-100.

35. Oliver, J.D. Recent findings on the viable but nonculturable state in pathogenic bacteria. FEMS Microbiol. Rev. 2010, 34, 415-425.

36. Moritz, M.M.; Flemming, H.K.; Wingender, J. Integration of Pseudomonas aeruginosa and Legionella pneumophila in drinking water biofilms grown on domestic plumbing materials. Int. J. Hyg. Environ. Hlth. 2010, 213, 190-197.

37. Wang, H.; Pryor, M.A.; Edwards, M.A.; Falkinham, J.O., III; Pruden, A. Effect of GAC pre-treatment and disinfectant on microbial community structure and opportunistic pathogen occurrence. Water Res. 2013, 47, 5760-5772.

38. Li, L.; Mendis, N.; Trigui, H.; Oliver, J.D.; Faucher, S.P. The importance of the viable but non-culturable state in human bacterial pathogens. Front. Microbiol. 2014, 5, 258, doi:10.3389/fmicrob.2014.00258.

39. Steinert, M.; Emödy, L.; Amann, R.; Hacker, J. Resuscitation of viable but nonculturable Legionella pneumophila Philadelphia JR32 by Acanthamoeba castellanii. Appl. Environ. Microbiol. 1997, 63, 2047-2053.

40. Sunenshine, R.H.; Wright, M.-O.; Maragakis, L.L.; Harris, A.D.; Song, X.; Hebden, J.; Cosgrove, S.E.; Anderson, A.; Carnell, J.; Jernigan, D.B.; et al. Multidrug-resistant Acinetobacter infection mortality rate and length of hospitalization. Emerg. Infect. Dis. 2007, 13, 97-103.

41. Bifulco, J.M.; Shirey, J.J.; Bissonette, G.K. Detection of Acinetobacter spp. in rural drinking water supplies. Appl. Environ. Microbiol. 1989, 55, 2214-2219.

42. Cateau, E.; Verdon, J.; Fernandez, B.; Hechard, Y.; Rodier, M.-H. Acanthamoeba sp. promotes the survival and growth of Acinetobacter baumanii. FEMS Microbiol. Lttrs. 2011, 319, 19-25.

43. Karumathi, D.P.; Yin, H.-B.; Kollanoor-Johny, A.; Venkitanarayanan, K. Effect of chlorine exposure on the survival and antibiotic gene expression of multidrug resistant Acinetobacter baumannii in water. Int. J. Environ. Res. Public Health 2014, 11, 1844-1854.

44. Hazen, T.C.; Fliermans, C.B.; Hirsch, R.P.; Esch, G.W. Prevalence and distribution of Aeromonas hydrophila in the United States. Appl. Environ. Microbial. 1978, 36, 731-738. 
45. Assanta, M.A.; Roy, D.; Montpetit, D. Adhesion of Aeromonas hydrophila to water distribution system pipes after different contact times. J. Food Protection 1998, 61, 1321-1329.

46. Sisti, M.; Albano, A.; Brandi, G. Bactericidal effect of chlorine on motile Aeromonas spp. in drinking water supplies and influence of temperature on disinfection efficacy. Lttrs. Appl. Microbiol. 1998, 26, 347-351.

47. Thomas, J.M.; Ashbolt, N.J. Do free-living amoebae in treated drinking water systems present an emerging health risk? Environ. Sci. Technol. 2011, 45, 860-869.

48. Ovrutsky, A.R.; Chan, E.D.; Kartalija, M.; Bai, X.; Jackson, M.; Gibbs, S.; Falkinham, J.O., III; Iseman, M.; Reynolds, G.; McDonnell, G.; et al. Co-occurrence of free-living amoebae and non-tuberculous mycobacteria in hospital water networks, and preferential growth of Mycobacterium avium in Acanthamoeba lenticula. Appl. Environ. Microbiol. 2013, 79, 3185-3192.

49. Thomas, V.; Herrera-Rimann, K.; Blanc, D.S.; Greub, G. Biodiversity of amoebae and amoeba-resisting bacteria in a hospital water network. Appl. Environ. Microbiol. 2006, 72, 2428-2438.

50. Thomas, V.; Bouchez, T.; Nicolas, V.; Robert, S.; Loret J.F.; Lévi. Y. Amoebae in domestic water systems: Resistance to disinfection treatments and implication in Legionella persistence. J. Appl. Microbiol. 2004, 97, 950-963.

51. Mullis, S.N.; Falkinham, J.O., III. Adherence and biofilm formation of Mycobacterium avium, Mycobacterium intracellulare and Mycobacterium abscessus to household plumbing materials. J. Appl. Microbiol. 2013, 115, 908-914.

52. Mauchline, J.W.S.; Araujo, R.; Wait, R.; Dowsett, A.B.; Dennis, P.J.; Keevil, C.W. Physiology and morphology of Legionella-pneumophila in continuous culture at low oxygen concentration. J. Gen. Microbiol. 1992, 138, 2371-2380.

53. Casini, B.; Buzzigoli, A.; Cristina M.L.; Spagnolo, A.M.; del Guidice, P.; Brusaferro, S.; Poscia, A.; Moscato, U.; Valentini P.; Baggiani, A.; et al. Long-term effects of hospital network disinfection on Legionella and other waterborne bacteria in an Italian university hospital. Infect. Control Hosp. Epi. 2014, 35, 293-299.

54. Sax, H.; Bloemberg, G.; Hasse, B.; Sommerstein, R.; Kohler, P.; Achermann, Y.; Rössle, M.; Falk, V.; Kuster, S.P.; Böttger, E.C., Weber, R. Prolonged outbreak of Mycobacterium chimaera infection after open-chest heart surgery. Clin. Infect. Dis. 2015, doi:10.1093/cid/civ198.

55. Wendel, A.F.; Kolbe-Busch, S.; Ressina, S.; Schulze-Röbbecke, R.; Kindgen-Milles, D.; Lorenz, C.; Pfeffer, K.; MacKensie, C.R. Detection and termination of an extended low-frequency hospital outbreak of GIM-1-producing Pseudomonas aeruginosa ST111 in Germany. Am. J. Infect. Control 2015, doi:10.1016/j.ajic.2015.02.024.

56. Falkinham, J.O., III. Nontuberculous mycobacteria from household plumbing of patients with nontuberculous mycobacteria disease. Emerg. Infect. Dis. 2011, 17, 419-424.

57. Bates, H.; Randall, S.K.; Rayssiguier, C.; Bridges, B.A.; Goodman, M.F.; Radman, M. Spontaneous and UV-induced mutations in Escherichia coli K-12 strains with altered or absent DNA polymerase I. J. Bacteriol. 1989, 171, 2480-2484.

58. Wang, H.; Edwards, M.A.; Falkinham, J.O., III; Pruden, A. Probiotic approach to pathogen control in premise plumbing systems? A review. Environ. Sci. Technol. 2013, 47, 10117-10128. 
59. Rhoads, W.J.; Pruden, A.; Edwards, M.A. Anticipating challenges with in-building disinfection for control of opportunistic pathogens. Water Environ. Res. 2014, 86, 540-549.

(C) 2015 by the authors; licensee MDPI, Basel, Switzerland. This article is an open access article distributed under the terms and conditions of the Creative Commons Attribution license (http://creativecommons.org/licenses/by/4.0/). 